\title{
Developing Racial Justice Allies in an Online Graduate Workshop Centering Latinx Students
}

\author{
Paul S. Hengesteg ${ }^{1} \cdot$ Erin Doran $^{1}$ (D) $\cdot$ Dian Squire $^{2}$ (iD \\ Accepted: 14 September 2020 / Published online: 14 October 2020 \\ (C) Springer Nature B.V. 2020
}

\begin{abstract}
This study presents data from an online course on Latinx Students in Higher Education taught at a Predominantly White Institution in the Midwest. This case study examines how students engage with content on Latinx issues across the P-20 educational pipeline to better understand and ultimately serve this population in their professional context using perspectives on allyship development and racial justice allyship. Students in the course demonstrated a commitment to social justice, but their journey to build allyship was not a straightforward process.
\end{abstract}

Keywords Ally identity development $\cdot$ Latinx students $\cdot$ Teaching

Paul S. Hengesteg, M.Ed. is a doctoral candidate in higher education administration at Iowa State University and is employed with ISU's Center for Excellence in Learning and Teaching. His research interests include social justice education, higher education faculty, as well as queer studies and feminisms. He has published/accepted pieces on Latinx experiences in higher education, engineering identity development for minoritized students, marketization of higher education, and the Scholarship of Learning and Teaching (SoTL).

Erin E. Doran, Ed.D. is an Assistant Professor of Higher Education and Community College Leadership at Iowa State University. Her research interests center on Latinx students in higher education; issues related to teaching and learning; and Hispanic-Serving Institutions.

Dian Squire, Ph.D. is an assistant professor in the Counseling-Student Affairs program in the College of Education at Northern Arizona University. His research examines how intersectional conceptualizations of race and racism inform institutional organization and practice and influence the life potentials of their constituent communities.

\author{
Erin Doran \\ edoran@iastate.edu \\ Paul S. Hengesteg \\ paulh@iastate.edu \\ Dian Squire \\ dian.squire@nau.edu
}

Extended author information available on the last page of the article 
Between 2000 and 2018, the college enrollment rates of Latinx ${ }^{1}$ students increased from $22 \%$ to $36 \%$, respectively (Hussar et al., 2020). Part of this growth has been attributed to increases in states apart from those where Latinx populations have been traditionally concentrated (e.g., California, Texas, Florida, New York, and Arizona). During the same period, however, the Latinx population in the Midwest grew by $24 \%$ (Flores, Lopez, \& Krogstad, 2019). Demonstrating this growth, Garcia's (2019) recent work on HispanicServing Institutions (HSIs) focused on such an institution in Illinois, and Excelencia in Education (2020a) reports a 93\% increase in the numbers of HSIs in the last decade. All these statistics point to a growth in Latinx students around the country. As postsecondary education institutions feel the effects of these increases in the short- and long-term, it is imperative that campus officials at all levels and in all areas of institutions (e.g., student affairs and academic affairs) are primed to work with this population in order to meet student success goals in reaffirming ways.

Many who serve students in higher education attend specific graduate programs in higher education administration and student affairs (HESA) aimed at supporting the holistic development and success of all students (NASPA/NASPA, 2015) and racial justice in line with NASPA's Strategic Imperative for Racial Justice and Decolonization (NASPA, n.d.). Certain competencies have been established in order for these educators to benchmark themselves, including in the realm of social justice and inclusion. In order to provide graduate students enrolled in such a program at a large public university in the Midwest with content that reflected these demographic changes especially around the needs of Latinx students, the second author received an institutional grant to develop a course centered Latinx students in the Midwest.

The purpose of this study is to analyze the student experience in this course through the lens of aspiring ally development (Edwards, 2006) and racial justice ally development (Reason, Roosa Millar, \& Scales, 2005). In particular, this study looks at how students built their knowledge and cultural competence for Latinx students and how they began to explain their role in supporting and advocating for Latinx students on their campuses and surrounding communities. Reason et al. (2005) defined racial justice allies as "Whites who are actively working to end racism and racial oppression" (p. 531). As is discussed later in this paper, we note that there were non-White students enrolled in this course, so we describe this allyship building process as one focused non-Latinx allies fighting against Latinx oppression. This analysis was guided by two research questions: 1) Why did master's and doctoral students enroll in a graduate course on Latinx students in higher education? and 2) How did the course on Latinx students in higher education help students build their capacity to serve as allies to Latinx students?

This study is unique because it specifically pertains to a graduate-level course with master's and doctoral-level students. Rather than focusing on the benefits of diversityrelated content in graduate programs (Morgan Consoli \& Marin, 2016), we looked at the course as allyship-building process for Latinx students. The role of allyship is important because HESA programs prepare student affairs administrators to play a significant role in student learning, engagement, and success (ACE, 1937; ACPA/NASPA, 2010, 2015).

\footnotetext{
${ }^{1}$ The pan-ethnic term "Latinx" was first documented online in 2004 and has grown in its usage substantially since 2015, especially in academia (Salinas, Doran, \& Swingle, 2020). The purpose of this term is to move beyond the masculine "Latina" the gender binary embedded in "Latina/o." While the U.S. Census Bureau has argued that "Latinx" is not a race, Gallegos and Ferdman (2011) explore how Latinx has functioned as both an ethnicity and race in the United States.
} 
These outcomes are particularly influenced by understandings of how systems of oppression, inequity, and injustice impact racially minoritized groups. Grounding ourselves in the literature of allyship as a process (i.e., Edwards, 2006; Reason et al., 2005), we analyzed student work over the course of the semester within this graduate workshop and how students expressed their engagement with the content and connected it to past, present, and future professional practice.

\section{Areas of Literature}

This section will highlight two important areas of consideration in this study: research that focused on ally development and the use of diversity courses in the higher education curriculum.

\section{Ally Development}

Our literature focuses on developing White people for allying with racially minoritized populations. As Landreman, Rasmussen, King, and Jiang (2007) point out, many studies of racial ally development focus on K-12 students (Matias \& Mackey, 2016; Yull \& Wilson, 2018), but research has also focused on either undergraduate students (Broido \& Reason, 2005; Cabrera, 2012; Linder, 2015; Reason et al., 2005; Ruiz, Cheng, Terrell, Lewis, \& Mattern, 2017), or faculty and staff (Landreman, Rasmussen, King, \& Jiang, 2007; Patton \& Bondi, 2015).

According to Robbins' (2016) study of ally development in White women enrolled in a HESA program, as a result of engaging with course content related to diversity and inclusion, "Eight of 11 participants used the phrase 'opening my eyes,' 'eye-opener,' or a similar phrase to describe experiences that awakened their consciousness to racism and White privilege" ( $\mathrm{p}$. 258). Engaging in course content that developed and shifted their understanding of racial inequity was a critical first step toward ally development in that it helped students understand their own positionality in the world. Robbins noted that once students were exposed to new ways of understanding racialized interactions in their lives, they desired even more knowledge. The students found that having a broader and deeper understanding of racism allowed them to better engage with their colleagues in difficult dialogues. In her development of an intersectional model of ally development, Linder (2015) worked with six students and recent alumnae who were White, anti-racist feminists. In the study, Linder found that as the students progressed through their understanding of their oppression as women, aspects of their Whiteness were causing them to "get stuck" in feelings of defensiveness, guilt or shame, and a fear of appearing racist. Linder (2015) continued to describe the journey undertaken by allies, "When White people understand the dynamics of racism (cognitive), feel the consequences of racism (emotional), and act on the combination of their knowledge and feelings (behavioral), a sustainable ally develops" (p. 548). Many times, coursework can be helpful to guide students through a learning journey.

Lastly, it is important to note that allyship does not fall only on White people, but that every person working in a higher education setting has the obligation to act as an accomplice in reaching racial justice. The Indigenous Action Network (2014) provided descriptors of various types of allies who enact types of actions people take that, in fact, do more harm to communities than help them. The group defines an accomplice as one who has a "fiercely 
unrelenting desire to achieve total liberation, with the land, and together...there is a 'we', and we most likely will have to work together...we fight back or forth, together, becoming complicit in a struggle towards liberation, we are accomplices" (p. 2). Whereas allyship may reify the savior mentality and perhaps various forms of oppression, being an accomplice means working with communities to support their needs as defined by the group. Squire (2019) wrote about the LGBTQ ally-industrial complex in student affairs, "Those engaging in this work must be sure-footed in their dedication to the cause of LGBTQ liberation and know that despite the challenges and triumphs that they will remain in collective action with those who they care about" (p. 199).

\section{The Role of Curriculum in Developing Allyship}

In understanding the developmental stages of allyship, we also note the hierarchy of curricular choices universities offer on diversity-related content. Higher education has long relied on diversity courses or ways for students to learn about marginalized identities and people (Bowman, 2010). Pragmatically for students, such courses may satisfy some kind of "diversity requirement," but, more broadly, the aim is to "heighten awareness of students to social problems confronting minorities [sic] and promote a more open attitude toward them" (Hogan \& Mallott, 2005, p. 116). Critical scholars have questioned how well such courses reveal and engage with systemic concerns of power and privilege rather than simply "telling about" communities of color (Gorski, 2009). Arguably, these diversity courses may stand apart from Ethnic Studies courses or social justice education because they celebrate diversity and multiculturalism rather than offer a meaningful critique of structural forms of oppression (e.g., racism, sexism, homophobia; Gérin-Lajoie, 2011). In the former, such as Black or African American studies, Latinx/Chicanx studies, Native American and Indigenous studies, and beyond, the experience of specific racial/ethnic populations in centered in relation to their experience in U.S. contexts with colonization, slavery, and de facto and de jure forms of oppression (Doran \& Hengesteg, 2020). Meanwhile, social justice education is defined as "the conscious and reflexive blend of content and process intended to enhance equity across multiple social identity groups, foster critical perspectives, and promote social action" (Carlisle, Jackson, \& George, 2006, p. 57).

\section{Theoretical Framework}

We combined two perspectives on allyship to frame this study: Edwards' (2006) social justice ally identity development model and Reason et al. (2005) racial justice allyship model. The Edwards (2006) model was useful because it intimates that being an ally to one group suggests an ability to be an ally to other/many groups (Edwards, 2006). As Edwards (2006) states, the self-reflective and fluid model "is intended to help inform aspiring allies and student affairs professionals seeking to develop social justice allies how individuals who already support diversity and social justice view what it means to be an ally" (p. 39). Edwards contends that this model is intended to be utilized by those who are either in the struggle toward broader social justice, such as student affairs professionals or other individuals employed within higher education.

Edwards (2006) identifies three primary statuses within his conceptual model: Aspiring Ally for Self-Interest, Aspiring Ally for Altruism, and Ally for Social Justice. Within the status 
known as Aspiring Ally for Self-Interest (AA-SI), an individual is likely motivated for selfish reasons, and focuses on overt examples of oppression without considering larger systems of inequity, potentially even denying their privilege or maintaining the status quo. Those in this status may want to be an ally to/for a specific person to whom they are close (i.e., sibling, parent, close friend). Very little self-reflection on the part of the aspiring ally occurs in this status because the focus of the ally is on the specific, targeted individual. Aspiring Ally for Altruism (AA-A), suggests that someone is understanding of privilege, but may not yet be attune to identifying the larger systems of oppression at play. Comparatively, a person who is in the Ally for Social Justice (A-SJ) status, works with members of the target group (as opposed to working over or working for the target group). These allies seek to disrupt systems, rather than overt acts or perpetrators, of injustice that will benefit all people - minoritized or dominant identity alike - with a sustained passion.

In their study toward developing a model of racial justice ally development, Reason et al. (2005) found that providing courses for White students to explore their dominant identity in context with one another and with action is positive toward ally development. This study, done with undergraduate students, suggests that students will take actions toward racial justice commensurate with their understanding of Whiteness. Where we felt this model was particularly useful was in understanding the ecological viewpoint of how college experiences help build racial justice allyship and that curricular experiences are a part of that process. One important implication of this model was the need to develop and advocate for coursework on race and race relations.

\section{Methodology}

This study utilized a single-case study methodology to guide the inquiry (Yin, 2017). More specifically, this case is revelatory in nature, meaning that the researchers had the opportunity to study a phenomenon previously unstudied or inaccessible in the research literature (Yin, 2017). As noted above, this course was unique in its design as it was unlike any other higher education courses offered at Iowa State University and one of few in the field widely, and the second author was unable to locate other institutions that focused on Latinx students in higher education with a specific focus on the Midwest context. Yin (2017) contended that case study is an appropriate method for researchers asking "how" and "why" questions, but have no control over behavioral events in a contemporary setting. Further, case studies identify a "case," or an individual, context, phenomenon, or problem in a real-life context that forms a bounded system for analysis (Hays \& Singh, 2012).

\section{Case Context: Institution}

The case is a course entitled Latinx Students in Higher Education, taught in the Spring 2018 semester at Iowa State University, a large, public Predominantly White Institution (PWI). Organizationally, the course was offered through the School of Education (SOE), which encompasses teaching, learning, and research activities across the P-20 educational continuum, with a strong focus on issues that pertain to social justice. Within the graduate education programs, an interdisciplinary graduate certificate is available in Education for Social Justice (ESJ), which many students find as an attractive way to take electives toward an additional credential while completing their major program of study. The course was designed so that it 
would count toward the certificate, and we assumed that students who are pursuing the certificate may already be predisposed to or have done more reflection on allyship. Enrollment in the course drew from master's and doctoral students from higher education (student affairs and community college leadership); K-12 education (teacher education; social foundations of education); and the ESJ certificate program. The student affairs program is a traditional, oncampus master's programs that prepares students for positions in a number of areas, including residence life, academic support, and advising. Graduates from the program often seek jobs nationally through the Oshkosh Placement Exchange or other professional outlets like NASPA.

The development of this course, which was funded by an institutional mini-grant, was prompted by various local and national events that framed students' decisions to enroll in the course. Iowa has a strong political culture, and its higher education institutions serve as important forums for presidential candidates to court voters. In 2015, then-candidate Donald Trump made a controversial visit to the campus during which students protested his statements on women and immigrants (Tendell, 2015). Months before the start of the course, Trump announced that he would rescind the Deferred Action for Childhood Arrivals (DACA) program started by the Obama administration. Iowa is also the location of a raid where Immigration and Customs Enforcement (ICE) raid of Postville, Iowa, where hundreds of undocumented workers at a meat processing factory were arrested, most of whom were Latinx. At the time, the raid was the largest ICE raid of its kind (Grey, Devlin, \& Goldsmith, 2009).

\section{Case Context: Course Content}

The curriculum of the course was designed by the second author, and the learning outcomes for the course were stated in the syllabus:

- Students will understand the growth of the Latinx demographic in the Midwest

- Students will be aware of experiences of Latinx students across institutional types;

- Students will be exposed to a number of programs developed in service to Latinx students and their success in higher education;

- Students will think of ways to adapt practices to their context and campus.

This course was offered as an asynchronous online workshop. Weekly, students were asked to write brief personal reflections on the readings as well as engage in an online, small-group discussion forum, which constituted a large proportion of the overall grade for the course. Among the group discussion prompts were, "How do we begin to dismantle these misconceptions so that we can start to have real conversations about the Latinx population, racism, systemic oppression, and so on?" from Week 3's discussion. In Week 15, students were asked to read excerpts from El Plan de Santa Barbara (a plan for Chicana/o/x higher education drafted in 1969) and asked, "What sticks out to you about this plan? What is still needed today? If updated, what might a new Chicanx plan for higher education (or education more broadly) look like?" In Week 2, students were asked in their personal reflections to think about a chapter on myths about Latinxs and to consider which might be common in the Midwest in particular and how to combat negative stereotypes about Latinxs.

There was a scaffolded assignment where students explored literature related to a specific topic of their choice (e.g., family engagement; Latinx student behaviors regarding financial 
aid; retention in STEM) by completing an annotated bibliography that they used to develop a program or intervention proposal. Students were also assigned to write a novel or autobiography by a Latinx author that spoke to Latinx culture and/or education issues in some way. Students in the course were given the opportunity to connect the content of the course across regional and local issues, communities, and histories.

\section{Data Sources}

This study draws from student assignment submissions and professor-student interactions. As the instructor, the second author was granted an IRB exemption as the data was collected under normal educational practices (IRB Exemption Category B1).

Participants Students in the course were notified at the beginning of class that online discussions, papers, and other assignment submissions would be de-identified and used as data. Students were given the chance to withdraw their data as part of the study both during and after the course completed, and none did so. Table 1 provides information on the students enrolled in this course.

Artifacts Used in the Analysis Process After the end of the semester, everything in the course's Canvas shell was treated as data, including group discussions and all students' assignments (weekly reflections, annotated bibliography, final program proposal). The data was downloaded from the university's learning management system, de-identified, and uploaded into Dedoose for coding. The documents used a combination of emotion and open coding (Saldaña, 2016) in the first round in order to identify emergent themes. Emotion coding looks at affective responses to the topic studied as recalled by the participants (Saldaña, 2016). Axial coding (Saldaña, 2016) was used in the second round to refine the codes and begin to make sense of the broader themes emerging from the data. The coding was done as a

Table 1 Student participants

\begin{tabular}{lllll}
\hline Pseudonym & Race/Ethnicity & Gender & Major & Level \\
\hline Michael & White & Male & Student Affairs & Master's \\
Lucinda & African-American & Female & Student Affairs & Master's \\
Maryann & White & Female & Education for Social Justice & Graduate Certificate \\
Carol & White & Female & Higher Education & Doctoral \\
Rafael & Latinx & Male & Student Affairs & Master's \\
Ann & White & Female & Student Affairs & Master's \\
Lydia & Latinx & Female & Student Affairs & Master's \\
Alex & White & Male & Social \& Culture Foundations of Education & Doctoral \\
Carter & White & Male & Student Affairs & Master's \\
Sally & White & Female & Higher Education & Master's \\
Elizabeth & White & Male & Student Affairs & Master's \\
Betsy & White & Female & Higher Education & Master's \\
Rebecca & White & Female & Social \& Cultural Foundations of Education & Doctoral \\
Kelly & White & Female & Higher Education & Doctoral \\
Angie & White/Latinx & Female & Student Affairs & Master's \\
Brenda & White & Female & Student Affairs & Master's \\
Jennifer & African-American & Female & Student Affairs & Master's \\
Karen & White & Female & Non-degree seeking & \\
\hline
\end{tabular}


collaborative and iterative process where the authors came together to discuss the codes as they were generated, to talk out places of disagreement, and ultimately to collectively decide how the codes generated broader themes.

\section{Researcher Positionalities}

Given that qualitative inquiry assumes that the researcher(s) is an instrument of the research itself, it is worth acknowledging our identities and positionalities briefly. We also paraphrase Patel's (2016) key reflexivity questions that ask: why this study, why us, and why now? All three authors currently work, worked, or go to school in Iowa. As people who live(d) in Iowa during a tumultuous time period around the election of the 45th president, we felt a certain duty to work alongside our own self-identified and other minoritized communities and potential future allies to work toward liberation and justice. Each of us holds multiply marginalized identities and identify as critical scholars who are interested in positively impacting higher education for all students. Additionally, each author has taught current and future educators and aims to infuse a socially just curriculum in their teachings. The first author is a doctoral student in the School of Education at the location of study, and identifies as a gay, White man. His teaching and research interests include faculty, the LGBTQ community, and teaching of social justice. The second author is a multi-ethnic (Latina/White) female who identifies strongly with her Latinx heritage having been born and raised on the U.S.-Mexico border who studies Latinx students in postsecondary education. The third author is a firstgeneration, queer, biracial Asian American man critical and decolonizing scholar who studies (mal)formations of race and racism in higher education and has written about student learning, curriculum for justice, and allyship.

\section{Validity and Trustworthiness}

We approached this work from a social constructivist paradigm, which leads us to believe in "pluralistic, interpretive, open-ended, and contextualized (e.g., sensitive to place and situation) perspectives toward reality" (Creswell \& Miller, 2000, p. 125-126). In line with this method, we worked toward two trustworthiness measures appropriate to the paradigm of this study, including thick description and prolonged engagement on the part of the second author as the instructor of the course (Creswell \& Miller, 2000). Through thick description, we provided as much detail as space allowed to describe the context of the course and quoted heavily from students' own words where possible. To the second, the data collection spanned the life of the course over 16 weeks. We also acknowledge the bias to believe students' sincerity in their assignment responses while understanding that it is possible that students responded to course materials in ways they anticipated would positively impact their grades in the course.

This study presents a few limitations. One limitation is our decision to focus only on course content and student submissions (i.e., discussion boards, reflections). Although we did not conduct interviews with the students, leaving some of our findings up to hermeneutic interpretation, we do believe there are clear opportunities here to build social justice allies through the creation of courses such as this one. However, our findings show promise that courses that expose students to new information which results in an identity disconnect for students leads to positive ally development. As some critics of ally development suggest, 
action is an important component of allyship; therefore, creating a longitudinal study would provide an opportunity to follow up with students after some time to determine what actions, if any, they have employed as an ally. Doing so would add richness to the findings. Finally, we note that the theoretical frameworks we employ focus on White allyship, and there were 5 students out of 18 who identified as racially minoritized students. Future studies might look at allyship development across racially minoritized categories.

\section{Findings}

Part of understanding the students' process of building their allyship toward Latinx students was in understanding the motivation behind students' decisions to enroll in this workshop in the first place. Students articulated a desire to know more about this growing demographic and acknowledged that Latinx student backgrounds and issues were topics they had little prior knowledge about or exposure to but knew they needed. As the course progressed, students' development as racial justice allies became more complicated as they connected past experience and knowledge (or lack of) to the current realities of Iowa and the broader educational landscape. As such, our findings are grouped into the following two themes. The first theme, knowledge and desire, indicates that students have some knowledge, but want to grow that knowledge base to better their practice as educators. The second theme, moments of learning and discomfort, suggests that developing an ally identity is not without its dissonant moments.

\section{Knowledge \& Desire}

We have sub-divided this theme into two parts. The first part relates to getting a baseline understanding of what the students know about Latinx issues in the Midwest when entering the class. The second part address the reasons - motivations - for enrolling in the course.

Assessing Current Knowledge In the first week, students were asked to identify themselves and explain what brought them to the course. Many contexts influenced the way the class was approached and received by the student participants. Several students had limited exposure to Latinx people and issues prior to the enrolling in the class, despite the reality that the population has grown significantly in the Midwest. Carter, a White male master's student, said in a group discussion, "Personally, I took this course because I don't know a lot about the Latinx population and the many ethnicities that comprise it." As future campus administrators, students like Michael, a White male master's student, also hoped that the course would give them important skills in their current and future praxis: "What brings me to the class is a desire to build greater cultural awareness and [to] be able to better serve students and other community members within the margins." Michael's comment in the group discussion suggests that in order to be better in practice, he needs more knowledge, more specific information.

Many students described their choice to enroll in the course in relation to their upbringings. Half of the students noted that they were from areas in Iowa with relatively large Latinx populations, and they expressed a desire to learn more about the history and culture of these neighbors. On the other hand, students continually reminded other students in their discussion responses that their childhoods happened in rural spaces without much diversity. Because interviews were not a method used in this study, it is 
unclear of the importance of significance of such statements; however, prior intentional and recognized exposure to Latinx groups might impact the types of knowledge needed and desire to learn more about Latinx groups.

Edwards' (2006) theory posits that building a sense of allyship is an ongoing process of self-reflection. Considering that students in the course experienced different reflective moments about their relationship to and knowledge of the Latinx community, the challenge of these classes is how to continue the self-reflection once the semester ends. For instance, Sally, an older White female in the class, expressed in a personal reflection to the instructor that the course prompted what she called an "identity crisis" for her and her work related to social justice. Sally said that she had a hard time understanding what her role as a White ally could be for those facing discrimination or oppression. She disclosed this relatively late in the class (the first week of April, more than halfway through the course), and it was unclear whether Sally will continue to think about and work through her personal questions or if she left them with the conclusion of the course.

Nine of the students in the course were finishing their master's program in Student Affairs and talked about the knowledge or empathy for Latinx students that they would take with them into their post-graduation positions. Interestingly, Rafael (Latinx male master's student) noted that his baccalaureate institution recently became a Hispanic-Serving Institution, and he was interested in returning to it with his deepened knowledge of Latinx students in higher education. The reflections on the semester were positive and reflected a sense of empowerment that students felt as they demonstrated a greater awareness and knowledge about Latinx students across the P-20 pipeline. Rafael ended his final reflection on the course with the statement, "I look forward to advocating, serving and working alongside many Latinx students and this course has provided me with great resources to continue to do that work."

Desire to Be an Ally Four of the students explicitly articulated that enrollment in the course aligned with their desire to be social justice allies. Lucinda, a Black female, spoke directly to her desire to be an ally in the week 1 group discussion: "I would like to use the knowledge I learn here about Latinx culture, history, etc., to be better equipped to stand in solidarity with these groups of people as I continue to strengthen and develop my social justice praxis." For Lucinda, her previously developed desire to be an ally was important in connecting with others who are on the margins of society. Similarly, Jennifer, a Black Master's student, was interested in the class because of her solid grounding in understanding Black and African American student concerns, but honoring the need to broaden that knowledge base. She reflected that she was:

really interested in the class because my research interest focus on low-income, firstgeneration, and students of color who participate in college access programs. I have a great wealth of knowledge about the experience of Black/African American students from personal experience, professional experience, and research but I want to know more about Latinx students [and] other students of color and their experiences. I thought this class would be a great way to learn about the students I serve and will continue to serve. Specifically, with Midwestern culture also being a new area for me this also sparked my interests. 
The idea of racial solidarity for Jennifer derived from her understanding of a shared subjugated positionality within a racial hierarchy and a recognition that systems of oppression are interlocked.

Angie had a similar reality for this course in the group discussion board. She wrote of her desire to connect with the stories and experiences of her elders:

I was also interested in this course since I identify as a biracial Latina (half-White, halfLatina), my great-grandparents immigrated from Mexico and during the process, they assimilated because of the pressure. Since most of the culture was lost through generations of my family I do not know as much as I would like to and hope this course will continue to help me understand the culture better and find me a way to connect some of the stories my grandpa would tell me about his experience here in the Midwest. I also know as a White-passing woman of color my experience is very different and I would like to understand how I can better serve students who don't hold the privileges I do.

Angie's reason for being in the class proved the most personal as she specifically spoke to her own family's assimilation to White, Midwestern culture and the desire to reclaim her Latina identity through this course. In this case, we understand Angie's desire to learn about a culture that is both her own, and also other. She noted that because of assimilationist pressures, Whiteness played a role in how she understood her experience even as a self-identified biracial Latina. This course was an opportunity for her to reclaim (portions of) her identity.

This theme relates to the previous knowledge of graduate students when enrolling in the course, as well as their motivations to take the class. We answer our first research question by articulating that students have some, albeit limited knowledge of the Latinx community in Iowa and the Midwest. However, students expressed a hunger for more information, particularly in pursuit of a graduate certificate and their ability to be better (i.e., more informed, supportive) educators. The next theme, which speaks to our second research question, articulates moments of learning and discomfort toward the goal of ally development.

\section{Moments of Learning and Discomfort}

Posts from the students on discussion boards or reflections provided opportunities to see the ways that new information was creating dissonance with students' previous knowledge and their identities. The students also spoke to ways this discomfort made them feel and how they might be allies moving forward. This second theme, which we also subdivided, addresses our second research question by articulating the ways that students built their capacity for allyship toward Latinx students. The 2 subthemes of this section are: 1) political connections and 2) emotional responses to allyship.

Political Connections By studying state policies, the class was able to view oppression - and allyship - from a structural standpoint, rather than at the individual level (i.e., simply not having information). This allowed the class to view allyship in relationship with political cognizance. For example, students were asked to read Martinez, Buntin, and Escalante's (2012) policy analysis of all 50 states in the U.S. and their treatment of Latinx residents in each state They were then asked in discussion how they responded to Iowa's "significantly exclusionary" (p. 65 ) classification. Some students suggested the ranking was disappointing, but others were not surprised. Brenda, a White female student who was from another state in the Midwest, said in 
the group discussion board that, "it seemed on par with my experiences and observations here." Lucinda, a Black woman from out of state, added her observations of exclusion as evidence of not being surprised by the ranking, "After being at Iowa State University for over a year and getting to see the blatant racism, xenophobia, and hyper-nationalism that happened on campus during the election period last year, this rating made sense."

Not all students based their lack of shock on the events witnessed on campus or within the community. Both of these White women noted the apparent disconnect between the overly harsh policy response to a seemingly non-issue. Sally noted in the discussion forum, "The legislative response seems disproportionate to the demographic impact," and Betsy agreed, adding:

This is consistent with the anti-Latinx and xenophobic sentiments I see expressed constantly in the Midwest. What is surprising, however, is the fact that Iowa has such a low percentage of foreign-born Latinx individuals, yet had introduced five exclusionary bills (p. 65). It seems as if Iowa is overreacting to a perceived problem that doesn't truly exist. This seems to stem from misconceptions and stereotypes surrounding Latinx populations. For some reason, White individuals see Latinx individuals as a real threat to their way of life.

As Angie, a White and Latina mixed-race woman, came to understand in the class, allyship is just as political as oppression. Despite the fact that she was not surprised by Iowa's exclusionary ranking, she stated in her group discussion post:

I'm embarrassed to admit that until recently I was never very interested in politics (part of my privilege), so I had no idea about the state level laws that could impact others' lives so drastically. I am starting to learn and educate myself more about laws and be a more active citizen.

In this passage, Angie acknowledged that her privileges allowed her to "check out" of the political process. Although it would be unfair to the students in the class to generalize their positions as such, it does raise the question of how much they view state-level policy-making as a driver of racism and their participation in the democratic process as a form of allyship.

Emotional Responses to Allyship As students engaged with the course material, they shared emotional responses to the content, which became a compelling tool for analysis. Aside from hesitancy with naming various Latinx groups, students expressed great discomfort in challenges related to a common cultural artifact of Iowa, "Iowa Nice." Gutsche (2012) talks about the concept of "Iowa Nice" as the phenomenon that limits conversation to only "nice" topics. By focusing on nice topics, residents then remove any opportunity to engage in conversations on topics such as race or racism for fear of upsetting the other person(s) - keeping the conversation "nice." "Nice" then becomes a form of oppression-by-erasure carried out by the people of Iowa (Gutsche, 2012).

The course incorporated real-life examples into online discussions, including the ICE raid in Postville, Iowa, and discussions around the current administration's rhetoric about Latinxs, challenged their concepts of "Iowa nice," or this prevailing notion that all people from Iowa are friendly to all in a political environment that has been openly hostile to Latinxs. Betsy, a White female master's student, described the current climate of Iowa as, 
We are ten years removed from the PostvilleRaids, and yet I feel as if we are in the early stages of a national-pride, anti-immigration movement led by Trump and his administration that has already caused a deep-rooted sense of unease among undocumented Latinx individuals. When you look at the evidence, there's no wonder individuals are living in fear. The week after Trump was inaugurated, I saw ICE come onto my street and take someone in custody.

At the end of the course, students were asked to reflect on the feelings they left the course with and the next steps they were ready to take in support of Latinx students. Students reported leaving the course with a sense of duty or empowerment toward serving Latinx students in their educational spaces. However, it is unknown how long their empowerment will last or if it fizzled out after the conclusion of the course. We recognize students' and faculty's very real propensity to "move on" from a class each semester.

\section{Discussion}

The Edwards (2006) social justice ally identity development model suggests that students may be in one of three statuses: aspiring ally for self-interest (AA-SI), aspiring ally for altruism (AA-A), and ally for social justice (A-SJ). Although Edwards provides hints in his discussion of the model that allow readers to get an idea of what each status means, he does not provide hard-and-fast rules as to how students responses such as ours might fit within the model. Further, the Edwards model is described from a theoretical perspective without providing empirical descriptions on the processes that aspiring allies have actually gone through in their journey. This study helps to describe those processes or events in with empirical data. Paired with the racial justice allyship model (Reason et al., 2005), we looked at how curricular experiences could helped students work toward their own developmental process toward allyship, particularly as allies for Latinx students.

At the beginning of the semester, students demonstrated a desire to learn more about Latinx students and to establish themselves as culturally competent educators in a variety of capacities (e.g., academic advisors, K-12 teachers, residence life staff). As the course progressed, students expressed dismay or discomfort at their lack of awareness about Latinx populations and about events that happened in their proverbial back yards. Notably, many explained this gap in their awareness to their upbringings in rural Iowa, even though there has been measurable population growth in these areas since at least the year 2000 (State Data Center, 2019). We remain skeptical of relying on the "small town defense" exhibited by students because experience tells us that privilege, broader social narratives, and structures like education play a major factor in the kinds of knowledge to which a person may have exposure. Indeed, color-evasiveness would indicate that students in fact ignore race as a deliberate act rather than a passive one (Annamma, Jackson, \& Morrison, 2017).

By discussing students' reasons for taking the course at the beginning of the semester, we noted that many students have the desire to be allies to Latinx students. Edwards (2006) noted that, "Individuals acting as Allies for Social Justice work with those from the oppressed group in collaboration and partnership to end the system of oppression" (p. 51, emphasis original). Their understanding of marginalization, and specifically racism, from a personal standpoint may indicate that they are A-SJs. Yet, Edwards (2006) tells us that allies are, by definition, part of the dominant group, complicating this assessment. 
The role of emotions is evident throughout all of the literature on White allyship and particular within the literature on the role White privilege plays in dismantling systemic oppression (DiAngelo, 2018; Robbins, 2016). Within the context of Iowa, emotionality was linked to ones grappling with the concept of "Iowa Nice". There was a sense of hesitation as students rectified their cultural upbringing with a newfound actualization that they needed to have conversations around race and racism in order to be fully allied with Latinx communities. In this sense, they were no longer allowed to engage in color-evasive ways, and instead, needed to recognize and name how racism played out in their communities, classrooms, and policies (Annamma, Jackson, \& Morrison, 2017; Gutsche, 2012; Linder, 2015; Robbins, 2016). These hesitations might also indicate a low lack of confidence in having these discussions.

Perhaps one of the shortfalls of Edwards's (2006) allyship model is that while it illustrates allyship as developmental and eternally reflective, it does not necessarily state how momentum is sustained over time for this development, especially once a diversity course ends. It may be that sustainability is implied in the A-SJ status, but that is not explicitly clear. In addition, due to the short nature of this course, there is no accountability for the students to actually implement their designed programs (their final assignment). This is important as we think back to the ally vs. accomplice discussion earlier in this manuscript and the notion that accomplice connotes action. We posit, then, the philosophical and pedagogical question: Is it realistic to assume action (i.e., accomplice status) when it is also necessary to provide basic information to reflect upon as a first step, all in a 15-week course?

Reason et al. (2005) developed an ecological model for explaining how the college experience impacts White students' racial justice ally development of which coursework related to race is part. A major finding of this study was that this development often happened in tandem with students coming to understand their Whiteness in relation to broader understandings of race, racialized experiences, and race relations. Therefore, it is important for those who take up this work to understand that if racial justice development is an endgoal, the teaching of content focused on racially minoritized groups cannot be separated from racial formation (Omi \& Winant, 2015) and Whiteness. In short, it is imperative for courses to take a more critical approach to content similar to Ethnic Studies or social justice education rather than the broader diversity course approach that describes social inequities without moving toward racial justice.

The impetus for this class was a growing Latinx demographic in the Midwest, a desire on the part of the instructor to offer a course that highlighted this growth, and to expose future educators and student affairs professionals to research that would help them serve this demographic. While students did not explicitly use the term "ally," their motivations for enrolling the course were to better understand this emerging community and how they could best serve them in their professional contexts. What this course shows is that the content is not most important; instead, the challenge of building future allies within a class is in how the instructor facilitates individual and group self-reflection, how they can move through the various stages of allyship (Edwards, 2006), and how the momentum of this growth can continue after the semester ends.

The use of the term allies is not without contention. For example, some practitioners and scholars prefer the term accomplice instead (Love, 2019; Powell \& Kelly, 2017; Squire, 2019; Yull \& Wilson, 2018). Authors in these alternative contentions wrestled with these terms and felt uneasy about using accomplice due to its connotation with the legal system, as did we. Some scholars and activists, on the other hand, favor the latter term because it connotes a 
person's willingness to speak and enact truth to power - especially when the stakes are at their highest (Indigenous Action Network, 2014; Squire, 2019). We favor allies because the term, at least as Edwards (2006) uses it, suggests a process of development. We agree that allyship is an ongoing process rather than an identity or a destination as well as honor the very real need for accomplices. Among the goals of the class were to raise awareness of Latinx students in educational contexts (perhaps very early awareness for some of the graduate students) and consider how the inequities presented inform socially-just continued praxis. Students were asked to develop a program for future practice, so action was inferred in the class, but not necessarily assumed or required. To that end, the conception of allyship is more congruent with the course itself.

\section{Implications}

The data presented in this study offer implications for HESA educators. First, HESA programs should explicitly explore demographic variables and experiences of Latinx students. This course focused on the Midwest, where the context is different from other parts of the country. However, it is worth noting that at least 1 student affairs graduate from this course expected to return to her hometown in the Midwest and pursue a job at a local community college, which is an Emerging Hispanic-Serving Institution (Excelencia in Education, 2020b). Considering that Hispanic-Serving Institutions are a growing sector of higher education institutions (Excelencia in Education, 2020a), it is crucial that student affairs programs expose their students to these institutions and to Latinx students, especially for programs where graduates end up geographically dispersed throughout the United States.

A well-developed course must be attuned such variances as well as the diversity among Latinxs themselves. In the broader struggle for racial justice, a course centering Latinxs should consider including content around anti-Blackness in the Latinx community and how to combat this phenomenon. HESA programs should include courses like this as a regularly offered elective or core component of their course of study. Relegating a course such as this one as an elective and/or a course that is not taught on a regular cycle furthers the marginality of Latinx populations and students. Relatedly, courses should not only include identity, but also explore how power, oppression play into the Latinx experience and how it interacts with Whiteness and White supremacy in U.S. society.

Finally, there are many reasons to offer online courses, and those reasons vary from department to department. At the time of this writing, the United States is in the thick of the COVID-19 pandemic that has forced a significant amount of courses online. We believe that one contribution of this study is in discussing how curriculum focused on a specific minoritized population can be delivered and helping others generate ideas about how racial justice allyship (and perhaps allyship to other causes) can be developed virtually. When given the chance to decide on course delivery format, educators should reflect on risks and rewards of a virtual classroom as compared to an in-person classroom. Specifically, instructors should make intentional decisions about how online education takes place. For instance, the third author creates multiple opportunities for students to meet "face-to-face" in online video discussion groups to process deep socially constructed topics like race and racism. These spaces allow students to verbally articulate emotions, knowledge, and their perspectives on the topics. 


\section{Conclusion}

Inspired in part from the growth of the Latinx population of Iowa (State Data Center, 2019), this study analyzed the motivations and experiences of graduate students in a course on Latinx students in higher education taught at a Predominantly White Institution. Through the lens of allyship development (Edwards, 2006) and racial justice allyship (Reason et al., 2005), the findings show that students demonstrated varying levels of ally development. Students displayed an overall genuine ethic of care toward Latinx students and an awareness that Latinx students comprise a rapidly increasing demographic, even in the Midwest. However, it was challenging for students to interrogate their privileges and placements within oppressive systems, which offered moments of discomfort as they interrogated their past experiences and assumptions about this population. Our findings suggest that the majority of the students provided comments that suggest they are Aspiring Allies for Altruism (Edwards, 2006) because they can identify systems of oppression, but primarily cognitively. This study illustrates how important coursework can build in building critical consciousness and cultural competence but also the limits of promoting long-term allyship development when focused content (that is, content focused on a specific population or issue) are confined to one semester.

Funding The corresponding author received a Teaching Innovation Grant from the College of Human Sciences at Iowa State University to develop the course described in this manuscript in the Spring 2017 semester. This is acknowledged in the manuscript text as well.

Data Availability The data and material from this study is not available for sharing, per the corresponding author's Institutional Review Board.

Conflict of Interest There are no conflicts of interest to declare with this study.

Code Availability Coding may be available upon request.

\section{References}

ACPA. (n.d.). Strategic imperative for racial justice and decolonization. Retrieved from https://www.myacpa. org/sirjd. Accessed 27 Sept 2020.

ACPA/NASPA (2010, 2015). Professional competency areas for student affairs educators. ACPA-College Student Educators International/NASPA - Student Affairs Administrators in Higher Education.

ACPA/NASPA. (2015). Professional compentency areas for student affairs educators. Retrieved from https://www.naspa.org/images/uploads/main/ACPA_NASPA_Professional_Competencies_FINAL.pdf. Accessed 27 Sept 2020.

American Council on Education Studies [ACE] (1937). The student personnel point of view. American Council on Education Studies.

Annamma, S.A., Jackson, D.D., \& Morrison, D. (2017). Conceptualizing color-evasiveness: using dis/ability critical race theory to expand a colorblind racial ideology in education and society. Race Ethnicity and Education, 20(2), 147-162. https://doi.org/10.1080/13613324.2016.1248837

Bowman, N. A. (2010). Disequilibrium and resolution: The nonlinear effects of diversity courses on well-being and orientations toward diversity. The Review of Higher Education, 33(4), 543-568. https://doi.org/10.1353 /rhe.0.0172

Broido, E. M., \& Reason, R. D. (2005). The development of social justice attitudes and actions: An overview of current understandings. New Directions for Student Services, 2005(110), 17-28. https://doi.org/10.1002 /ss. 162

Cabrera, N. L. (2012). Working through whiteness: White, male college students challenging racism. The Review of Higher Education, 35(3), 375-401. DOI: https://doi.org/10.1353/rhe.2012.0020 
Carlisle, L. R., Jackson, B. W., \& George, A. (2006). Principles of social justice education: The social justice education in schools project. Equity \& Excellence in Education, 39(1), 55-64. https://doi.org/10.1080 $/ 10665680500478809$

Creswell, J. W., \& Miller, D. L. (2000). Determining validity in qualitative inquiry. Theory Into Practice, 39(3), 124-130.

DiAngelo, R. (2018). White fragility: Why it's so hard for white people to talk about racism. Boston, MA: Beacon Press.

Doran, E., \& Hengesteg, P. (2020). Ethnic studies, U.S. curriculum. In M.E. David \& M.J. Amey (eds.), The SAGE encyclopedia of higher education (pp. 481-482). Thousand Oaks, CA: SAGE. https://doi.org/10.4135 /9781529714395.n183

Edwards, K.E. (2006). Aspiring social justice ally identity development: A conceptual model. NASPA Journal, 43(4), 39-60.

Excelencia in Education. (2020a). Hispanic-serving institutions (HSIs): 2018-19. Washington, DC: Excelencia in Education. Retrieved from https://www.edexcelencia.org/Hispanic-Serving-Institutions-HSIs-2018-2019

Excelencia in Education. (2020b). Emerging Hispanic-serving institutions (HSIs): 2018-19. Washington, DC: Excelencia in Education. Retrieved from https://www.edexcelencia.org/Emerging-Hispanic-ServingInstitutions-EHSIs-2018-2019

Flores, A., Lopez, M.H., \& Krogstad, J.M. (2019, July 8). U.S. Hispanic population reached new high in 2018, but growth has slowed. Washington, DC: Pew Hispanic Center. Retrieved from https://www.pewresearch. org/fact-tank/2019/07/08/u-s-hispanic-population-reached-new-high-in-2018-but-growth-has-slowed/

Gallegos, P.V., \& Ferdman, B.M. (2011). Latina and Latino ethnoracial identity orientations: A dynamic and developmental perspective. In C. Wijeyesinghe \& B.W. Jackson (eds.), New perspectives on racial identity development: Integrating emerging frameworks (2 ${ }^{\text {nd }}$ ed., 51-80). New York: New York University Press.

Garcia, G.A. (2019). Becoming Hispanic-Serving Institutions: Opportunities for colleges and universities. Baltimore, MD: Johns Hopkins University Press.

Gérin-Lajoie, D. (2011). Multicultural education: Nothing more than folklore? Canadian Issues, 24, 24-27. Retrieved from https://acs-aec.ca/wp-content/uploads/2019/05/CITC-2011-Spring-Printemps-L-1. pdf\#page=26 Accessed 25 June 2020.

Gorski, P. C. (2009). What we're teaching teachers: An analysis of multicultural teacher education coursework syllabi. Teaching and Teacher Education, 25, 309-318.

Grey, M., Devlin, M., \& Goldsmith, A. (2009). Postville, U.S.A.: Surviving diversity in small-town America. Boston, MA: GemmaMedia.

Gutsche, R. E., Jr. (2012). "This ain't the ghetto": Diaspora, discourse, and dealing with "Iowa Nice.” Poroi 8(2), 1-4. Retrieved from https://ir.uiowa.edu/cgi/viewcontent.cgi?article=1140\&context=poroi

Hays, D.G., \& Singh, A.A. (2012). Qualitative inquiry in clinical and educational settings. New York, NY: The Guilford Press.

Hogan, D. E., \& Mallott, M. (2005). Changing racial prejudice through diversity education. Journal of College Student Development, 46(2), 115-125. https://doi.org/10.1353/csd.2005.0015

Hussar, B., Zhang, J, Hein, S., Wang, K., Roberts, A., Cui, J., Smith, M., Bullock Mann, F., Barmer, A., \& Dilig, R. (2020). The condition of education 2020. Washington, DC: Institute for Education Sciences, National Center for Education States. Retrieved from https://nces.ed.gov/pubsearch/pubsinfo. asp?pubid=2020144. Accessed 26 June 2020.

Landreman, L. M., Rasmussen, C. J., King, P. M., \& Jiang, C. X. (2007). A phenomenological study of the development of university educators' critical Cconsciousness. Journal of College Student Development, 48(3), 275-296. https://doi.org/10.1353/csd.2007.0027

Linder, C. (2015). Navigating guilt, shame, and fear of appearing racist: A conceptual model of antiracist white feminist identity development. Journal of College Student Development, 56(6), 535-550. https://doi. org/10.1353/csd.2015.0057

Love, B.L. (2019). We want to do more than survive: Abolitionist teaching and the pursuit of educational freedom. Boston, MA: Beacon Press.

Martinez, R., Buntin, J. T., \& Escalante, W. (2012). The policy dimensions of the context of reception for immigrants (and Latinos) in the Midwest. In Cambio de Colores: Latinos in the Heartland: Migration and Shifting Human Landscapes: Proceedings of the 10th Annual Conference: Kansas City, Missouri, June 810, 2011. Columbia, Mo.: University of Missouri. University of Missouri-Columbia. Cambio Center.

Matias, C. E., \& Mackey, J. (2016). Breakin' down Whiteness in antiracist teaching: Introducing Critical Whiteness Pedagogy. The Urban Review, 48(1), 32-50. https://doi.org/10.1007/s11256-015-0344-7

Morgan Consoli, M. L., \& Marin, P. (2016). Teaching diversity in the graduate classroom: The instructor, the students, the classroom, or all of the above? Journal of Diversity in Higher Education, 9(2), 143-157. https://doi.org/10.1037/a0039716 
Omi, M., \& Winant, H. (2015). Racial formation in the United States. New York, NY: Routledge.

Patel, L. (2016). Decolonizing educational research: From ownership to answerability. New York: Routledge.

Patton, L. D., \& Bondi, S. (2015). Nice White men or social justice allies?: Using critical race theory to examine how White male faculty and administrators engage in ally work. Race Ethnicity and Education, 18(4), 488514. https://doi.org/10.1080/13613324.2014.1000289

Powell, J., \& Kelly, A. (2017). Accomplices in the academy in the age of Black Lives Matter. Journal of Critical Thought and Praxis, 6(2), 42-65. https://doi.org/10.31274/jctp-180810-73

Reason, R. D., Roosa Millar, E. A., \& Scales, T. C. (2005). Toward a model of racial justice Ally development. Journal of College Student Development, 46(5), 530-546. https://doi.org/10.1353/csd.2005.0054

Robbins, C. K. (2016). White women, racial identity, and learning about racism in graduate preparation programs. Journal of Student Affairs Research and Practice, 53(3), 256-268. https://doi.org/10.1080 /19496591.2016.1143834

Ruiz, B. A., Cheng, K.-W., Terrell, B. C. C., Lewis, K. A., \& Mattern, M. C. (2017). For us, by us: Exploring constructions of student activism and university support. Higher Education Politics \& Economics, 3(2), article 2 .

Saldaña, J. (2016). The coding manual for qualitative researchers $\left(^{\text {rd }}\right.$ ed.). Thousand Oaks, CA: Sage Publications.

Salinas, C., Doran, E.E., \& Swingle, E.C. (2020). Community colleges' use of the term "Latinx." New Directions for Community Colleges, 190, 9-20. https://doi.org/10.1002/cc.20383

Squire, D. (2019). Ending allies through the eradication of the ally (industrial) complex. In E. Zamani-Gallaher, D. D. Choudhuri, \& J. Taylor (Eds.), Rethinking LGBTQIA students and collegiate contexts: Identities, policies, and campus climate (pp. 186-203). London, UK: Routledge

State Data Center. (2019). Latinos in Iowa: 2019. Des Moines, IA: Iowa Data Center. Retrieved from https://www.iowadatacenter.org/Publications/latinos2019.pdf. Accessed 3 Sept 2020.

Tendell, M. (2015, September 13). Woman rips students' Trump protest poster. Iowa State Daily. Retrieved from http://www.iowastatedaily.com/news/state/article_6637bd2a-5a61-11e5-af1d-a35596d96c5c.html.

Yin, R. K. (2017). Case study research and applications: Design and methods ( $6^{\text {th }}$ ed). Thousand Oaks, CA: SAGE.

Yull, D. G., \& Wilson, M. A. F. (2018). Allies, accomplices, or troublemakers: Black families and scholar activists working for social justice in a race-conscious parent engagement program. Critical Education, 9(8), $1-18$.

Publisher's Note Springer Nature remains neutral with regard to jurisdictional claims in published maps and institutional affiliations.

\section{Affiliations}

\section{Paul S. Hengesteg ${ }^{1} \cdot$ Erin Doran $^{1} \cdot$ Dian Squire $^{2}$}

1 School of Education, Iowa State University, 901 Stange Road, Ames, IA 50011, USA

2 Department of Educational Psychology, Northern Arizona University, Room 110 Building 27, Eastburn Education, $801 \mathrm{~S}$ Knoles Dr, Flagstaff, AZ 86011, USA 